\title{
Radiotherapy-Induced Fatigue in Breast Cancer Patients
}

\author{
Lidia Kowalczyk $^{\mathrm{a}}$ Christine Deutschmann $^{\mathrm{b}}$ Richard Crevenna ${ }^{\mathrm{c}}$ \\ Stefan Konrad ${ }^{d}$ Christian F. Singer ${ }^{b}$ Alex Farr $^{b}$ \\ ${ }^{a}$ Clinical Unit of Anesthesiology and Perioperative Intensive-Care Medicine, University of \\ Veterinary Medicine, Vienna, Austria; ${ }^{b}$ Department of Obstetrics and Gynecology, Division of \\ Gynecology and Gynecologic Oncology, Medical University of Vienna, Vienna, Austria; ${ }^{\mathrm{C} D e p a r t m e n t}$ of \\ Physical Medicine, Rehabilitation and Occupational Medicine, Medical University of Vienna, Vienna, Austria; \\ ${ }^{\mathrm{d}}$ Department of Radiation Oncology, Medical University of Vienna, Vienna, Austria
}

\section{Keywords}

Radiotherapy · Breast cancer · Fatigue .

Radiotherapy-induced fatigue $\cdot$ Side effects

\begin{abstract}
Background: A large proportion of breast cancer patients who undergo adjuvant radiotherapy suffer from radiotherapy-induced fatigue. The possible causative factors of this specific side effect are diverse. Summary: Prevalence, duration, and severity of radiotherapy-induced fatigue are dependent on the type of radiotherapy, as well as on the irradiated volume, dose scheme, on the number of radiation fields, the combination with other treatments, diurnal rhythm, smoking, and time-to-hospitalization. Recommended treatments include non-pharmacologic interventions, such as physical and psychosocial interventions. Pharmacologic therapies include treatment with methylphenidate and modafinil. In addition to its early detection with standardized instruments, adequate education to breast cancer patients about risks and predisposing factors of radiotherapy-induced fatigue is essential. Multidimensional strategies help to maintain the patients' quality of life and therefore guarantee treatment adherence and efficacy. Key Messages: Radiotherapy-induced fatigue is an underreported, underdiagnosed, and undertreated side effect. This review provides an overview of radiotherapy-induced fatigue in breast cancer patients receiving adjuvant radiotherapy.
\end{abstract}

\section{Introduction}

Adjuvant radiotherapy (RT) is the standard treatment for more than $90 \%$ of breast cancer (BC) patients, aiming to decrease locoregional recurrence and improve overall survival [1,2]. Despite its beneficial role, numerous side effects are associated with RT, and among the most common is RT-induced fatigue (RIF) [3]. In particular, up to $77 \%$ of BC patients who undergo RT suffer from RIF as a disorder, characterized by a state of generalized weakness with a pronounced inability to summon sufficient energy to accomplish daily activities $[1,4]$. Despite the high incidence rate, the symptom lacks a clear definition. The National Comprehensive Cancer Network (NCCN) defined RIF as a clinical subtype of cancer-related fatigue (CRF) that either arises during RT (acute RIF) or continues afterwards (chronic RIF). RIF is a distressing, persistent, and subjective sense of physical, emotional, or cognitive tiredness or exhaustion, related to cancer or cancer treatment that is not proportional to recent activity, and interferes with normal functioning $[5,6]$. Although RIF possibly compromises patients' treatment adherence [7], it is still underreported, underdiagnosed and undertreated $[5,8]$. This narrative review provides a comprehensive overview of RIF in BC patients who are undergoing adjuvant RT.

Author L.K. is deceased. 


\section{Pathophysiology}

Multiple factors have been proposed to cause RIF Some factors include genetics (e.g., DNA damage and telomere length), hypothalamic-pituitary-adrenal axis dysregulation, 5-hydroxytryptophan neurotransmitter dysregulation, and alterations in the adenosine-triphosphate (ATP) muscle metabolism. Other factors include endocrine disturbances (reduction in estrogen and testosterone), mitochondrial dysfunction, cytokine dysregulation, inflammation and immune response, anemia, circadian rhythm disruption, disruption in the bloodbrain barrier, and psychological mechanisms [3, 9-15].

Regarding mitochondrial dysfunction as a potential cause of RIF, the following pathophysiological pathway is being proposed. During RT, the mitochondrial membrane integrity is disrupted, and radiation may lead to a reduction of mitochondrial capacity to utilize oxygen and synthesize (ATP) [16, 17]. Side effects arise when ionizing radiation produces reactive oxygen species (ROS) that cause oxidative damage in late responding healthy tissues. The initial burst of ROS can subsequently lead to point mutations in mitochondrial DNA and further propagate ROS production by the dysfunctional mitochondria. This results in the accumulation of oxidative stress and a prolonged inflammation state $[12,18]$. Studies have also indicated that RIF is associated with anemia and functional iron deficiency $[12,15,18,19]$. ROS produced during RT can cause membrane changes, including lipid peroxidation, phospholipid hydrolysis, and disulfide bridge formation. The cytoskeleton may be affected due to changes in the cell membrane. This process results in the hemolysis of red blood cells and hemoglobin leakage [20]. Red blood cell count, hemoglobin and hematocrit were found to correlate with the severity of fatigue during external beam radiation therapy (EBRT), suggesting that stabilizing these levels may prevent the worsening of fatigue symptoms during EBRT [19].

\section{Severity and Assessment}

In general, fatigue can be classified according to its severity by using grades from 1 to 3 . Grade 1 would be "fatigue relieved by rest," "fatigue not relieved by rest, limiting instrumental activities of daily living" is grade 2, and "fatigue not relieved by rest, limiting self-care activities of daily living" is grade 3. Apart from this classification, objective measurement of fatigue remains a significant challenge. There is no fatigue-specific standardized assessment tool or scoring system to define the severity grade accurately $[10,21]$. For both CRF and RIF, assessment by a single-item symptom checklist has led to a certain underestimation in several studies [3]. Current- ly, subjective questionnaires like the Multidimensional Fatigue Inventory, Revised Piper Fatigue Scale, Brief Fatigue Inventory, Lee Fatigue Scale, Functional Assessment of Chronic Illness Therapy, European Organization for Research and Treatment of Cancer Quality of Life Questionnaire, or the Visual Analogue Scale are used to asses CRF [22-24].

Besides the diversified choice of questionnaire instruments used in the studies, the time point of fatigue evaluation differed strongly. The available studies included time points, such as during the appointment with the radiation oncologist, prior to starting RT, before starting $\mathrm{RT}$, at the beginning of RT, during the first week of RT, or no specification of the starting time point given. Regarding the total number of fatigue assessments within the study, protocols vary from one to four different protocols used [15, 25-32]. The results emphasize that standardization of the timing of the fatigue evaluation and the fatigue assessment tool still needs to be established. An overview of the most prevalent scales to measure RIF is presented in Table 1 [15, 27, 33-39].

\section{Impact of Irradiation}

It is well known that the prevalence, duration, and severity of fatigue depend on the type of RT, the irradiated volume and dose scheme, and on the combination with other treatments, as patients receiving combined therapies (e.g., chemotherapy plus RT) showed the highest fatigue scores [2, 3, 9, 40-42]. For some years now, hypofractionation has been considered the standard treatment in whole breast irradiation for early-stage BC without lymph node involvement. The UK Trialists' Collaborative Group and Whelan et al. [43] were able to demonstrate equal oncological safety using 15-16 fractions of $2.66 \mathrm{~Gy}$, compared to the standard fractionation scheme using 25-28 fractions of $2.0 \mathrm{~Gy}$ [43-45]. Although the single dose is higher, hypofractionated schemes are associated with fewer side effects, such as RIF, due to the reduced total dose and shorter treatment duration ( 3 instead of 5-6 weeks) [46].

Apart from the fractionation, treatment volumes to the region have an impact on the side effects of adjuvant RT [47]. Whole breast irradiation has been the standard of care after breast-conserving surgery for years. However, most of the local recurrences appear close to the tumor bed, so that efforts were made to reduce the treatment volume around the resected tumor. The hypothesis is that external beam accelerated partial breast irradiation (EB-APBI) with a safety margin of surrounding tissue might reduce side effects while maintaining the high rate of local control seen with whole breast radiation [48]. However, recently published data from two prospective 
Table 1. Assessment tools to measure fatigue in BC patients

\begin{tabular}{|c|c|c|c|c|}
\hline Instrument & Brief description & $\begin{array}{l}\text { Patients, } \\
n\end{array}$ & $\begin{array}{l}\text { Year of } \\
\text { publication }\end{array}$ & $\begin{array}{l}\text { Ref. } \\
\text { No. }\end{array}$ \\
\hline $\begin{array}{l}\text { Fatigue Symptom } \\
\text { Inventory (FSI) }\end{array}$ & $\begin{array}{l}\text { 11-point scale: } 0 \text { (not present) to } 10 \text { (as bad as you can imagine); } 4 \text { items rate the severity } \\
\text { of fatigue within the past week; } 7 \text { items assess the degree to which fatigue is judged to } \\
\text { interfere with the general level of activity, ability to bathe and dress, normal work activity, } \\
\text { ability to concentrate, relations with others, enjoyment of life, and mood in the past week; } \\
\text { frequency is measured by the number of days with fatigue in the past week }\end{array}$ & 1,129 & 2005 & 33 \\
\hline Lee Fatigue Scale (LFS) & $\begin{array}{l}18 \text {-item scale with } 13 \text { items assessing fatigue and } 5 \text { items assessing energy; each item is } \\
\text { rated on a } 0 \text { - } 10 \text { numeric rating scale; total score is calculated as the mean of all items with } \\
\text { higher scores indicating greater fatigue severity; validated cut-off scores for clinically } \\
\text { meaningful levels of fatigue ( } \geq 3.2 \text { for morning fatigue, } \geq 5.6 \text { for evening fatigue) and } \\
\text { energy ( } \geq 6.2 \text { for morning energy, } \geq 3.5 \text { for evening energy) }\end{array}$ & 75 & 1991 & 34 \\
\hline $\begin{array}{l}\text { Functional Assessment } \\
\text { of Cancer Therapy: } \\
\text { Fatigue (FACT-F) }\end{array}$ & $\begin{array}{l}\text { 13-item fatigue subscale, uses a 5-point Likert self-report scale ranging from } 0 \text { (not at all) } \\
\text { to } 4 \text { (very much); total score (sum of all items) ranges from } 0 \text { (worst condition) to } 52 \text { (best } \\
\text { condition); the score is calculated after re-parameterization of items } 7 \text { (I have energy) and } \\
8 \text { (I am able to do my usual activities) for which } 0 \text { is the worst condition and } 4 \text { the best } \\
\text { condition owing to the inverse relationship to the other } 11 \text { subscale items }\end{array}$ & 164 & 2018 & 35 \\
\hline $\begin{array}{l}\text { Functional Assessment } \\
\text { of Cancer Therapy: } \\
\text { Fatigue-General (FACT-G) }\end{array}$ & $\begin{array}{l}\text { 27-item scale: } 4 \text { sub-scales assessing physical wellbeing (PWB, } 0-28) \text {, functional wellbeing } \\
\text { (FWB, } 0-28) \text {, social/family well-being (SWB, } 0-28) \text {, and emotional wellbeing (EWB, } 0-24) \text {; } \\
\text { with higher scores indicating better quality of life }\end{array}$ & $\begin{array}{l}164 \\
141 \\
116\end{array}$ & $\begin{array}{l}2018 \\
2011 \\
2004\end{array}$ & $\begin{array}{l}35 \\
36 \\
15\end{array}$ \\
\hline $\begin{array}{l}\text { Visual Analogue Scale } \\
\text { (VAS) }\end{array}$ & $\begin{array}{l}\text { Single-item scale with } 2 \text { endpoints; no standardized stem questions and anchors (examples } \\
\text { for stem questions: energy level, quality of life, ability to perform daily activities; examples } \\
\text { for anchors: } 0=\text { exhausted, } 100=\text { have energy; } 0=\text { very bad, } 100=\text { very good); patients } \\
\text { make a mark on the VAS line to describe the point between the } 2 \text { anchors that best reflects } \\
\text { their fatigue status }\end{array}$ & 42 & 2009 & 27 \\
\hline $\begin{array}{l}\text { Functional Assessment } \\
\text { of Chronic Illness Therapy } \\
\text { (FACIT) }\end{array}$ & $\begin{array}{l}\text { In total } 13 \text { items: originally developed as an addition to the Functional Assessment of } \\
\text { Cancer Therapy (FACT) measurement system, forms the FACT-Fatigue (FACT-F) } \\
\text { together with the FACT-G }\end{array}$ & $\begin{array}{l}42 \\
58\end{array}$ & $\begin{array}{l}2009 \\
2019\end{array}$ & $\begin{array}{l}27 \\
37\end{array}$ \\
\hline $\begin{array}{l}\text { Brief Fatigue Inventory } \\
\text { Scale (BFI) }\end{array}$ & $\begin{array}{l}\text { In total } 9 \text { items: } 3 \text { items focusing on fatigue severity (fatigue at present, usual level and } \\
\text { worst level of fatigue within the past } 24 \mathrm{~h} \text { ) and } 6 \text { items to assess the impact of fatigue on } \\
\text { areas of daily functioning during the past } 24 \mathrm{~h} \text { (daily activity, mood, walking, work, } \\
\text { enjoyment of life, and relations with others); each item scores between } 0 \text { and 10; global } \\
\text { fatigue score is calculated by averaging all } 9 \mathrm{BFI} \text { items; higher scores indicate worse fatigue } \\
\text { and greater interference; global fatigue score cut-offs according to NCCN Clinical Practice } \\
\text { Guidelines: } \geq 4 \text { : no-mild fatigue }(0-3) \text { and moderate-severe fatigue (4-10) }\end{array}$ & 90 & 2010 & 38 \\
\hline PFS-12 & $\begin{array}{l}\text { In total } 12 \text { items: shortened version of the } 22 \text {-item revised Piper Fatigue Scale (PFS-R) } \\
\text { containing } 4 \text { subscales (behavior, affect, sensory and cognition) }\end{array}$ & 799 & 2012 & 39 \\
\hline
\end{tabular}

trials showed conflicting results regarding the equivalence to whole breast irradiation. Of note, side effects like RIF occurred less frequently $[49,50]$.

A study enrolled 30 early-stage BC patients receiving either partial breast RT, whole-breast RT, or MammoSite brachytherapy with a total dose of $34 \mathrm{~Gy}$, or 3D conformal RT with a full dose of $50 \mathrm{~Gy}$. The patients with partial breast RT showed lower rates of fatigue; women who received whole breast RT reported worsened fatigue over time [9]. In another study with 362 older women undergoing breast-conserving therapy for early-stage $\mathrm{BC}$, two types of accelerated partial breast irradiation were compared: intraoperative electron RT and EB-APBI with 10 $\times 3.85$ Gy [51]. The cross-sectional analysis showed significantly worse fatigue symptoms in intraoperative electron RT patients than in EB-APBI patients, which normalized after 3 months.

\section{Risk Factors and Prevention}

Pretreatment fatigue levels have been proposed as an essential risk factor for fatigue development during RT [25]. Diagnosing fatigue and recognizing it as a predictor for this condition during treatment within the first appointments seems to be of uttermost importance. Other factors influencing the grade of severity of RIF that have been described in the literature include the diurnal rhythm, where morning fatigue appears to be more affected by biologic factors and evening fatigue by behavioral factors. Another factor is smoking, with smokers experiencing considerably more fatigue than non-smokers. Time-to-hospitalization appears to influence the grade of severity of RIF, with significantly worse symptoms of fatigue in patients who had to travel 2 or more hours compared to patients who had to travel $<2 \mathrm{~h}[22]$. Factors such 
as stress, anxiety, depression, a weakened physical condition, diarrhea, malnourishment, and anemia possibly further deteriorate fatigue [22]. Geinitz et al. [52] observed a significant increase in pretreatment fatigue levels compared to posttreatment values. In women with depression and anxiety, fatigue levels were reported to persist for more than 2 years after the termination of RT. Contrary to that, disease staging and neoadjuvant chemotherapy did not impact the severity of fatigue in a study performed by Lavdaniti et al. [26].

Anticipation and early recognition of the individual risk for RIF could lead to possible preventive measures, such as prehabilitation instead of rehabilitation. A multimodal, multidisciplinary approach may be necessary to prevent RIF, including psychosocial intervention, physical exercise, and medications to address the contributing factors of RIF. As heme levels seem to have an impact on the incidence of RIF upon completion of EBRT, their stabilization is vital to prevent the worsening of fatigue symptoms during treatment [53]. Patients with increased age and high baseline fatigue levels are at risk of experiencing severe RIF [47]. In 2004, in a prospective study with 52 early BC patients undergoing adjuvant RT, Wratten et al. [15] reported that RIF appeared to plateau between week 4 of treatment and 2 weeks after treatment; fatigue was beginning to settle by 6 weeks after treatment. In their study, significant fatigue was predicted by a higher baseline fatigue score, red blood cell count, neutrophil count, and D-dimer level. Baseline fatigue correlated with higher body mass index and altered levels of C-reactive protein, soluble thrombomodulin, tissue plasminogen activator, von Willebrand factor antigen, interleukin-6, ICAM-1, hemoglobin, red blood cells, monocyte, and neutrophil counts. The most predictive factors for RIF in their study were a higher baseline fatigue level and more elevated baseline neutrophils and red blood cell counts. Results of a feasibility study presented in 2018, aiming to evaluate behavioral interventions in early $\mathrm{BC}$ patients with RIF, are awaited and they will undoubtedly be of interest in this context [54].

\section{Chronic Fatigue}

The impact of fatigue and debilitating tiredness is the loss of independence and impaired physical and mental function. In the mid-1990s an international working group developed a definition of the chronic fatigue syndrome. The description included requiring a person to experience 6 or more months of chronic fatigue of new or definite onset, that is not substantially alleviated by rest, not the result of ongoing exertion, and results in substantial reductions in occupational, social, and personal activities [55]. In most BC patients who undergo adjuvant
$\mathrm{RT}$, fatigue severity scores increase significantly from the beginning to half the duration of RT. They then remain elevated until the end of the treatment. After completion of RT, severity scores decreased to pretreatment scores within $4-8$ weeks $[22,38,52,56]$.

In contrast, previous studies have reported that up to $40 \%$ of patients were still suffering from RIF 1 year after completing adjuvant RT [36], or even 5-10 years following the completion of adjuvant RT [57]. The chronification of fatigue appears to correlate with psychological distress; patients with pretreatment elevated fatigue, anxiety, or depression were shown to be at risk for the chronic state $[3,52]$. Chronic fatigue can again lead to depression, impaired cognitive function, sleep disturbance, decreased physical activity, and the deterioration of the individual's quality of life $[5,10,58]$. Chronic fatigue may also influence the patient's compliance and, therefore, impact the efficiency of anticancer treatments $[1,9,10,36,57,58]$.

\section{Different Treatment Approaches}

Clinical practice guidelines are available to assist physicians in the management of RIF [59-63]. According to the NCCN, physical therapy and occupational therapy are recommended as the interventions of choice in patients with RIF [5]. The NCCN also recommends psychosocial interventions, such as cognitive-behavioral therapy, psycho-educational therapy, supportive-expressive therapy, nutritional guidance, hygiene, stimulus control, and sleep restriction [64]. Besides the non-pharmacologic treatment approaches, the NCCN advises the use of psychostimulants, such as methylphenidate and modafinil, after excluding other causes of fatigue like pain, anxiety, depression, anemia, sleep alteration, nutritional factors, and other comorbidities [64].

Non-pharmacologic treatment approaches include music therapy, yoga, and polarity therapy $[27,31,32,35]$. During and after RT, patients are recommended to take 150 min of "moderate-intensity exercise" per week (e.g., walking 30 min 5 days per week). Most of these exercises involve range of motion/flexibility, muscle strength, aerobic training, and mind/body fitness [65]. A randomized controlled trial about yoga's impact on inflammation, mood, and fatigue in BC survivors showed that immediate posttreatment fatigue was lower in patients who practiced yoga 3 months after completing treatment. Vitality was also higher in the yoga group, even directly after treatment [66]. With regards to yoga, the NCCN advises being cautious in cases of bone metastasis, thrombocytopenia, anemia, fever, active infection, and secondary limitations due to metastasis or other diseases [64]. A large meta-analysis, including $738 \mathrm{BC}$ patients, reported that 
exercise during RT was significantly more effective in reducing RIF than a control intervention (e.g., management of pain or nausea) [1]. Statistically significant benefits of supervised, combined aerobic resistance exercise regarding fatigue were shown.

\section{Physical Medicine and Rehabilitation}

In cancer pre- and rehabilitation, exercise is a very suitable means to reduce fatigue and improve the overall quality of life and participation [67-71]. Improvement of muscular strength, endurance capacity, sensorimotor functions, and flexibility seems to be of high clinical relevance concerning the overall quality of life, general health, survival, and return to work [67-71]. There are recent international recommendations for exercise in cancer patients, which serve as a guide for the fitness and health care professionals working with cancer survivors [71]. Cancer survivors can safely engage in exercise to restore physical functioning, enhance the quality of life, and mitigate CRF [71].

In some cases, cancer patients are not able to perform systematic and regular exercise due to different painful musculoskeletal conditions, such as plantar fasciitis or calcaneal spur, calcifying tendinopathy of the shoulder, tennis elbow, or Achilles tendinopathy [67, 68, 72]. In most cases, such painful musculoskeletal conditions prohibit active participation in exercise programs and therefore have to be treated before starting vigorous exercise $[67,68,72]$.

Physical Medicine and Rehabilitation (PM\&R) is a specialty with competencies in diagnostics and therapy, as well as coordination of the multi-professional and interdisciplinary rehabilitation teams [67, 68]. It is needed in all phases of medical care, from the prevention of diseases to palliative medicine, with the model of the International Classification of Functioning, Disability and Health as a basis [67]. Cancer pre- and rehabilitation includes many treatment approaches from $\mathrm{PM} \& \mathrm{R}$, which have been shown to reduce musculoskeletal pain. They are prescribed depending on the individual needs, abilities, and objectives of each patient $[67,68]$. Mechanical therapy is a modality that includes exercise, physiotherapy, water and immersion therapy, occupational therapy, massages, and special massages like lymphatic massage, ultrasound, extracorporeal shock-wave treatment, and extension. Another modality is electrical therapy, including low-frequency, middle-frequency, and high-frequency therapy, such as transcutaneous electrical nerve stimulation, galvanic baths, and short-wave diathermy. Thermotherapy includes the application of heat or cold, while phototherapy includes ultraviolet light, so-called cooled red light, and infrared light. Balneology and climate ther-
Table 2. Available treatment options for fatigue in $\mathrm{BC}$ patients

\section{Non-pharmacologic \\ interventions}

Physical interventions

PM\&R: e.g., physical therapy, occupational therapy,

programs, yoga

Psychosocial interventions

e.g., cognitive-behavioural therapy associated with

hypnosis, psycho-educational therapy, supportive-

expressive therapy, nutritional guidance, hygiene,

stimulus control, sleep restriction moderate-intensity physical exercises, stretching

\section{Pharmacologic} interventions

Psychostimulants e.g., methylphenidate, modaphenyl apy include baths, mud, and different climatic conditions, which have been shown to be effective in muscular relaxation, pain reduction, and improvement in the flexibility of structures [67-70].

Several years ago, malignant tumors, metastasis, multiple myeloma, and lymphoma were considered contraindications for treatment by using physical modalities $[68,72]$. However, these historical paradigms have changed in the past $[68,72]$. Today, physical modalities are only contraindicated at the tumor site but should be used in cancer patients for pain relief and mobilization only by qualified personnel. Especially, extracorporeal shock-wave treatment seems to be a very effective, safe, and time- and cost-efficient conservative modality for the treatment of musculoskeletal disorders in cancer patients [72]. After pain reduction by using physical modalities, exercise programs to improve muscular strength, endurance capacity, and improvement of the quality of life can be started in almost all cancer patients $[67,68]$. A general summary of the available treatment options for cancer patients with fatigue is summarized in Table 2.

\section{Conclusion}

In $\mathrm{BC}$ patients who undergo adjuvant RT, RIF is underreported, underdiagnosed and undertreated. RIF may become a chronic state with subsequent non-compliance, which further compromises treatment efficacy. It is essential to evaluate patients for their potential risk and to adequately inform them about predisposing factors and treatment options to prevent and treat fatigue. Standardization of the evaluation and assessment tools need to be established to ensure the full reliability of study results. Adequate management should involve an early start after cancer diagnosis and before commencing cancer treatment using a multimodal, multidisciplinary approach to prevent high severity and chronification. 


\section{Conflict of Interest Statement}

The authors have no conflicts of interest to declare.

\section{Funding Sources}

The authors received no financial support for the preparation of this manuscript.

\section{Author Contributions}

L.K., C.D., and A.F. reviewed the literature; L.K., C.D., R.C., S.K., and A.F. prepared the manuscript; C.F.S. provided clinical and scientifical support; all authors approved the final version of the manuscript.

\section{References}

1 Lipsett A, Barrett S, Haruna F, Mustian K, O'Donovan A. The impact of exercise during adjuvant radiotherapy for breast cancer on fatigue and quality of life: A systematic review and meta-analysis. Breast. 2017 Apr;32:14455.

2 EBCTCG (Early Breast Cancer Trialists' Collaborative Group); McGale P, Taylor C, Correa C, Cutter D, Duane F, Ewertz M, et al. Effect of radiotherapy after mastectomy and axillary surgery on 10-year recurrence and 20-year breast cancer mortality: meta-analysis of individual patient data for 8135 women in 22 randomised trials. Lancet. 2014 Jun;383: 2127-35.

3 Jereczek-Fossa BA, Marsiglia HR, Orecchia R. Radiotherapy-related fatigue. Crit Rev Oncol Hematol. 2002 Mar;41(3):317-25.

4 Manir KS, Bhadra K, Kumar G, Manna A, Patra NB, Sarkar SK. Fatigue in breast cancer patients on adjuvant treatment: course and prevalence. Indian J Palliat Care. 2012 May; 18(2):109-16.

5 Berger AM, Mooney K, Alvarez-Perez A, Breitbart WS, Carpenter KM, Cella D, et al.; National comprehensive cancer network. Cancer-Related Fatigue, Version 2.2015. J Natl Compr Canc Netw. 2015 Aug;13(8): 1012-39.

6 Piper BF, Cella D. Cancer-related fatigue: definitions and clinical subtypes. J Natl Compr Canc Netw. 2010 Aug;8(8):958-66.

7 Morrow GR, Andrews PL, Hickok JT, Roscoe JA, Matteson S. Fatigue associated with cancer and its treatment. Support Care Cancer. 2002 Jul;10(5):389-98.

8 Alcântara-Silva TR, Freitas-Junior R, Freitas NM, Machado GD. Fatigue related to radiotherapy for breast and/or gynaecological cancer: a systematic review. J Clin Nurs. 2013 Oct; 22(19-20):2679-86

9 Albuquerque K, Tell D, Lobo P, Millbrandt L, Mathews HL, Janusek LW. Impact of partial versus whole breast radiation therapy on fatigue, perceived stress, quality of life and natural killer cell activity in women with breast cancer. BMC Cancer. 2012 Jun;12(1):251.

10 Hsiao CP, Daly B, Saligan LN. The Etiology and management of radiotherapy-induced fatigue. Expert Rev Qual Life Cancer Care. 2016;1(4):323-8

11 Bower JE, Ganz PA, Tao ML, Hu W, Belin TR, Sepah S, et al. Inflammatory biomarkers and fatigue during radiation therapy for breast and prostate cancer. Clin Cancer Res. 2009 Sep;15(17):5534-40.
12 Feng LR, Suy S, Collins SP, Saligan LN. The role of TRAIL in fatigue induced by repeated stress from radiotherapy. J Psychiatr Res. 2017 Aug;91:130-8.

13 Courtier N, Gambling T, Enright S, BarrettLee P, Abraham J, Mason MD. Psychological and immunological characteristics of fatigued women undergoing radiotherapy for earlystage breast cancer. Support Care Cancer. 2013 Jan;21(1):173-81.

14 Torres MA, Pace TW, Liu T, Felger JC, Mister $\mathrm{D}$, Doho GH, et al. Predictors of depression in breast cancer patients treated with radiation: role of prior chemotherapy and nuclear factor kappa B. Cancer. 2013 Jun;119(11):1951-9.

15 Wratten C, Kilmurray J, Nash S, Seldon M, Hamilton CS, O’Brien PC, et al. Fatigue during breast radiotherapy and its relationship to biological factors. Int J Radiat Oncol Biol Phys. 2004 May;59(1):160-7.

16 Hsiao CP, Wang D, Kaushal A, Chen MK, Saligan L. Differential expression of genes related to mitochondrial biogenesis and bioenergetics in fatigued prostate cancer men receiving external beam radiation therapy. J Pain Symptom Manage. 2014 Dec;48(6):1080-90.

17 Eghbal MA, Pennefather PS, O’Brien PJ. H2S cytotoxicity mechanism involves reactive oxygen species formation and mitochondrial depolarisation. Toxicology. 2004 Oct;203(13):69-76.

18 Azzam EI, Jay-Gerin JP, Pain D. Ionizing radiation-induced metabolic oxidative stress and prolonged cell injury. Cancer Lett. 2012 Dec;327(1-2):48-60.

19 Lind M, Vernon C, Cruickshank D, Wilkinson P, Littlewood T, Stuart N, et al. The level of haemoglobin in anaemic cancer patients correlates positively with quality of life. Br J Cancer. 2002 Apr;86(8):1243-9.

20 Khoshbin AR, Mohamadabadi F, Vafaeian F, Babania A, Akbarian S, Khandozi R, et al. The effect of radiotherapy and chemotherapy on osmotic fragility of red blood cells and plasma levels of malondialdehyde in patients with breast cancer. Rep Pract Oncol Radiother. 2015 Jul-Aug;20(4):305-8.

21 Filler K, Saligan LN. Defining cancer-related fatigue for biomarker discovery. Support Care Cancer. 2016 Jan;24(1):5-7.

22 Dhruva A, Dodd M, Paul SM, Cooper BA, Lee $\mathrm{K}$, West C, et al. Trajectories of fatigue in patients with breast cancer before, during, and after radiation therapy. Cancer Nurs. 2010 May-Jun;33(3):201-12.
23 Luthy C, Cedraschi C, Pugliesi A, Di Silvestro K, Mugnier-Konrad B, Rapiti E, et al. Patients' views about causes and preferences for the management of cancer-related fatigue-a case for non-congruence with the physicians? Support Care Cancer. 2011 Mar;19(3):36370 .

24 Andrykowski MA, Schmidt JE, Salsman JM Beacham AO, Jacobsen PB. Use of a case definition approach to identify cancer-related fatigue in women undergoing adjuvant therapy for breast cancer. J Clin Oncol. 2005 Sep; 23(27):6613-22.

25 Ahlberg K, Ekman T, Gaston-Johansson F. The experience of fatigue, other symptoms and global quality of life during radiotherapy for uterine cancer. Int J Nurs Stud. 2005 May; 42(4):377-86

26 Lavdaniti M, Patiraki E, Dafni U, Katapodi M, Papathanasoglou E, Sotiropoulou A. Prospective assessment of fatigue and health status in Greek patients with breast cancer undergoing adjuvant radiotherapy. Oncol Nurs Forum. 2006 May;33(3):603-10.

27 Montgomery GH, Kangas M, David D, Hallquist MN, Green S, Bovbjerg DH, et al. Fatigue during breast cancer radiotherapy: an initial randomized study of cognitive-behavioral therapy plus hypnosis. Health Psychol. 2009 May;28(3):317-22.

28 Hwang JH, Chang HJ, Shim YH, Park WH, Park W, Huh SJ, et al. Effects of supervised exercise therapy in patients receiving radiotherapy for breast cancer. Yonsei Med J. 2008 Jun;49(3):443-50.

29 Geinitz H, Zimmermann FB, Stoll P, Thamm R, Kaffenberger W, Ansorg K, et al. Fatigue, serum cytokine levels, and blood cell counts during radiotherapy of patients with breast cancer. Int J Radiat Oncol Biol Phys. 2001 Nov;51(3):691-8.

30 Lee TS, Kilbreath SL, Refshauge KM, Pendlebury SC, Beith JM, Lee MJ. Quality of life of women treated with radiotherapy for breast cancer. Support Care Cancer. 2008 Apr;16(4): 399-405.

31 Moadel AB, Shah C, Wylie-Rosett J, Harris MS, Patel SR, Hall CB, et al. Randomized controlled trial of yoga among a multiethnic sample of breast cancer patients: effects on quality of life. J Clin Oncol. 2007 Oct;25(28):438795.

32 Roscoe JA, Matteson SE, Mustian KM, Padmanaban D, Morrow GR. Treatment of radiotherapy-induced fatigue through a nonpharmacological approach. Integr Cancer Ther. 2005 Mar;4(1):8-13. 
33 Hickok JT, Morrow GR, Roscoe JA, Mustian $\mathrm{K}$, Okunieff P. Occurrence, severity, and longitudinal course of twelve common symptoms in 1129 consecutive patients during radiotherapy for cancer. J Pain Symptom Manage. 2005 Nov;30(5):433-42.

34 Lee KA, Hicks G, Nino-Murcia G. Validity and reliability of a scale to assess fatigue. Psychiatry Res. 1991 Mar;36(3):291-8.

35 Alcântara-Silva TR, de Freitas-Junior R, Freitas NM, de Paula Junior W, da Silva DJ, Machado GD, et al. Music Therapy Reduces Radiotherapy-Induced Fatigue in Patients With Breast or Gynecological Cancer: A Randomized Trial. Integr Cancer Ther. 2018 Sep; 17(3):628-35

36 Noal S, Levy C, Hardouin A, Rieux C, Heutte $\mathrm{N}$, Ségura C, et al. One-year longitudinal study of fatigue, cognitive functions, and quality of life after adjuvant radiotherapy for breast cancer. Int J Radiat Oncol Biol Phys. 2011 Nov;81(3):795-803.

37 Abed J, Dolan L, Jones J, Dinniwell R. Impact of Self-Reported Exercise on Recounted Levels of Fatigue and Anxiety in Early-Stage Breast Cancer Radiation Therapy Patients. J Med Imaging Radiat Sci. 2019 Jun;50(2):227-33.

38 Janaki MG, Kadam AR, Mukesh S, Nirmala S, Ponni A, Ramesh BS, et al. Magnitude of fatigue in cancer patients receiving radiotherapy and its short term effect on quality of life. J Cancer Res Ther. 2010 Jan-Mar;6(1):22-6.

39 Reeve BB, Stover AM, Alfano CM, Smith AW, Ballard-Barbash R, Bernstein L, et al. The Piper Fatigue Scale-12 (PFS-12): psychometric findings and item reduction in a cohort of breast cancer survivors. Breast Cancer Res Treat. 2012 Nov;136(1):9-20.

40 Murchison S, Soo J, Kassam A, Ingledew PA, Hamilton S. Breast Cancer Patients' Perceptions of Adjuvant Radiotherapy: an Assessment of Pre-Treatment Knowledge and Informational Needs. J Cancer Educ. 2019. doi: 10.1007/s13187-019-01507-4.

41 Langston B, Armes J, Levy A, Tidey E, Ream E. The prevalence and severity of fatigue in men with prostate cancer: a systematic review of the literature. Support Care Cancer. 2013 Jun;21(6):1761-71.

42 Schwartz AL, Nail LM, Chen S, Meek P, Barsevick AM, King ME, et al. Fatigue patterns observed in patients receiving chemotherapy and radiotherapy. Cancer Invest. 2000;18(1): 11-9.

43 Whelan TJ, Pignol JP, Levine MN, Julian JA, MacKenzie R, Parpia S, et al. Long-term results of hypofractionated radiation therapy for breast cancer. N Engl J Med. 2010 Feb; 362(6):513-20.

44 Haviland JS, Owen JR, Dewar JA, Agrawal RK, Barrett J, Barrett-Lee PJ, et al.; START Trialists' Group. The UK Standardisation of Breast Radiotherapy (START) trials of radiotherapy hypofractionation for treatment of early breast cancer: 10 -year follow-up results of two randomised controlled trials. Lancet Oncol. 2013 Oct;14(11):1086-94.

45 Bentzen SM, Agrawal RK, Aird EG, Barrett JM, Barrett-Lee PJ, Bliss JM, et al.; START Trialists' Group. The UK Standardisation of Breast Radiotherapy (START) Trial A of radiotherapy hypofractionation for treatment of early breast cancer: a randomised trial. Lancet Oncol. 2008 Apr;9(4):331-41.

46 Shaitelman SF, Schlembach PJ, Arzu I, Ballo M, Bloom ES, Buchholz D, et al. Acute and Short-term Toxic Effects of Conventionally Fractionated vs Hypofractionated WholeBreast Irradiation: A Randomized Clinical Trial. JAMA Oncol. 2015 Oct;1(7):931-41.

47 Taunk NK, Haffty BG, Chen S, Khan AJ, Nelson $\mathrm{C}$, Pierce $\mathrm{D}$, et al. Comparison of radiation-induced fatigue across 3 different radiotherapeutic methods for early stage breast cancer. Cancer. 2011 Sep;117(18):4116-24.

48 Mannino M, Yarnold JR. Local relapse rates are falling after breast conserving surgery and systemic therapy for early breast cancer: can radiotherapy ever be safely withheld? Radiother Oncol. 2009 Jan;90(1):14-22.

49 Whelan TJ, Julian JA, Berrang TS, Kim DH, Germain I, Nichol AM, et al.; RAPID Trial Investigators. External beam accelerated partial breast irradiation versus whole breast irradiation after breast conserving surgery in women with ductal carcinoma in situ and node-negative breast cancer (RAPID): a randomised controlled trial. Lancet. 2019 Dec;394(10215): 2165-72.

50 Vicini FA, Cecchini RS, White JR, Arthur DW, Julian TB, Rabinovitch RA, et al. Longterm primary results of accelerated partial breast irradiation after breast-conserving surgery for early-stage breast cancer: a randomised, phase 3, equivalence trial. Lancet. 2019 Dec;394(10215):2155-64.

51 Jacobs DH, Horeweg N, Straver M, Roeloffzen EM, Speijer G, Merkus J, et al. Health-related quality of life of breast cancer patients after accelerated partial breast irradiation using intraoperative or external beam radiotherapy technique. Breast. 2019 Aug;46:32-9.

52 Geinitz H, Zimmermann FB, Thamm R, Keller M, Busch R, Molls M. Fatigue in patients with adjuvant radiation therapy for breast cancer: long-term follow-up. J Cancer Res Clin Oncol. 2004 Jun;130(6):327-33.

53 Feng L, Chen MK, Lukkahatai N, Hsiao CP, Kaushal A, Sechrest L, et al. Clinical Predictors of Fatigue in Men With Non-Metastatic Prostate Cancer Receiving External Beam Radiation Therapy. Clin J Oncol Nurs. 2015 Dec; 19(6):744-50.

54 Courtier N, Gaze S, Armes J, Smith A, Radley L, Armytage J, et al. ACTIVE - a randomised feasibility trial study protocol of a behavioural intervention to reduce fatigue in women undergoing radiotherapy for early breast cancer: study protocol. Pilot Feasibility Stud. 2018 Jun;4(1):85.

55 Fukuda K, Straus SE, Hickie I, Sharpe MC, Dobbins JG, Komaroff A; International Chronic Fatigue Syndrome Study Group. The chronic fatigue syndrome: a comprehensive approach to its definition and study. Ann Intern Med. 1994 Dec;121(12):953-9.

56 Donovan KA, Jacobsen PB, Andrykowski MA, Winters EM, Balducci L, Malik U, et al. Course of fatigue in women receiving chemotherapy and/or radiotherapy for early stage breast cancer. J Pain Symptom Manage. 2004 Oct;28(4):373-80.

57 Hofman M, Ryan JL, Figueroa-Moseley CD, Jean-Pierre P, Morrow GR. Cancer-related fa- tigue: the scale of the problem. Oncologist. 2007;12(Suppl 1):4-10.

58 Pinto BM, Dunsiger S, Waldemore M. Physical activity and psychosocial benefits among breast cancer patients. Psychooncology. 2013 Oct;22(10):2193-9.

59 Bower JE. Cancer-related fatigue-mechanisms, risk factors, and treatments. Nat Rev Clin Oncol. 2014 Oct;11(10):597-609.

60 Mücke M, Mochamat, Cuhls H, PeuckmannPost V, Minton O, Stone P, et al. Pharmacological treatments for fatigue associated with palliative care: executive summary of a $\mathrm{Co}-$ chrane Collaboration systematic review. J Cachexia Sarcopenia Muscle. 2016 Mar;7(1):23-7.

61 Mustian KM, Alfano CM, Heckler C, Kleckner AS, Kleckner IR, Leach CR, et al. Comparison of Pharmaceutical, Psychological, and Exercise Treatments for Cancer-Related Fatigue: A Meta-analysis. JAMA Oncol. 2017 Jul;3(7):961-8.

62 Bennett S, Pigott A, Beller EM, Haines T, Meredith P, Delaney C. Educational interventions for the management of cancer-related fatigue in adults. Cochrane Database Syst Rev. 2016 Nov; 11:CD008144.

63 Cramp F, Byron-Daniel J. Exercise for the management of cancer-related fatigue in adults. Cochrane Database Syst Rev. 2012 Nov;11:CD006145.

64 Berger AM, Abernethy AP, Atkinson A, Barsevick AM, Breitbart WS, Cella D, et al. NCCN Clinical Practice Guidelines Cancerrelated fatigue. J Natl Compr Canc Netw. 2010 Aug;8(8):904-31.

65 Stubbe CE, Valero M. Complementary strategies for the management of radiation therapy side effects. J Adv Pract Oncol. 2013 Jul;4(4): 219-31.

66 Kiecolt-Glaser JK, Bennett JM, Andridge R, Peng J, Shapiro CL, Malarkey WB, et al. Yoga's impact on inflammation, mood, and fatigue in breast cancer survivors: a randomized controlled trial. J Clin Oncol. 2014 Apr; 32(10):1040-9.

67 Crevenna R, Kainberger F, Wiltschke C, Marosi C, Wolzt M, Cenik F, et al. Cancer rehabilitation: current trends and practices within an Austrian University Hospital Center. Disabil Rehabil. 2020 Jan;42(1):2-7.

68 Crevenna R. Physikalische Medizin und Rehabilitation. Vienna: Facultas; 2018.

69 Hasenoehrl T, Keilani M, Palma S, Crevenna R. Resistance exercise and breast cancer related lymphedema - a systematic review update. Disabil Rehabil. 2020 Jan;42(1):26-35.

70 Cenik F, Mähr B, Palma S, Keilani M, Nowotny T, Crevenna R. Role of physical medicine for cancer rehabilitation and return to work under the premise of the "Wiedereingliederungsteilzeitgesetz". Wien Klin Wochenschr. 2019 Oct;131(19-20):455-61.

71 Campbell KL, Winters-Stone KM, Wiskemann J, May AM, Schwartz AL, Courneya KS, et al. Exercise Guidelines for Cancer Survivors: Consensus Statement from International Multidisciplinary Roundtable. Med Sci Sports Exerc. 2019 Nov;51(11):2375-90.

72 Crevenna R, Mickel M, Keilani M. Extracorporeal shock wave therapy in the supportive care and rehabilitation of cancer patients. Support Care Cancer. 2019 Nov;27(11):4039-41. 